\title{
Survival of pediatric patients with primary immunodeficiencies in a public hospital in Western Mexico
}

\author{
María E. Núñez-Núñez, M.D. ${ }^{a}$, Juan C. Lona-Reyes, M.D. ${ }^{b, c}$, Sandra I. Cortés-González, M.D. ${ }^{d, e}$, \\ Regina Mallinalli Navarro-Martín del Campo, M.D.f, Ana L. Orozco-Alvarado, M.D.f, \\ Oscar González-Ramella, M.D. ${ }^{f}$ and Luis Gustavo Orozco-Alatorre, M.D. ${ }^{d, f}$
}

\begin{abstract}
A case series of primary immunodeficiencies is presented and outcome measures associated with survival among patients $\leq 16$ years old are described. Diagnoses were made based on the criteria by the International Union of Immunological Societies. Survival was analyzed using Kaplan-Meier curves. Between 2004 and 2019, 40 patients were diagnosed with primary immunodeficiencies. The most common were immunodeficiencies affecting humoral and cell-mediated immunity $(32.5 \%)$ and predominantly antibody deficiencies $(32.5 \%)$. The median age at the onset of symptoms and at the time of diagnosis was 3.01 and 10.4 months, respectively. Thirty-five percent of patients died, and the risk was higher among those with immunodeficiencies affecting humoral and cell-mediated immunity and those who developed clinical manifestations and were diagnosed in the first 6 months of life. Key words: primary immunodeficiency diseases, severe combined immunodeficiency, primary antibody deficiency, immune system, immune system diseases.
\end{abstract}

http: / / dx.doi.org/10.5546/aap.2021.eng.202

To cite:Núñez-Núñez ME, Lona-Reyes JC, Cortés-GonzálezSI, Mallinalli Navarro-Martín del Campo R, et al. Survival of pediatric patients with primary immunodeficiencies in a public hospital in Western Mexico. Arch Argent Pediatr 2021;119(3):202-207.

a. Hospital Civil de Guadalajara "Dr. Juan I. Menchaca", Department of Pediatrics, Division of Pediatric Allergy and Immunology. Guadalajara, Jalisco, México.

b. Hospital Civil de Guadalajara "Dr. Juan I. Menchaca", Department of Pediatrics, Division of Infectious Diseases, Guadalajara, Jalisco, México.

c. Universidad de Guadalajara, University Center of Tonalá, Tonalá, Jalisco, México.

d. Hospital Civil de Guadalajara "Dr. Juan I. Menchaca”, Department of Pediatrics, Guadalajara, Jalisco, Mexico.

e. Universidad de Guadalajara, Health Science University Center, Guadalajara, Jalisco, Mexico.

f. Hospital Civil de Guadalajara "Dr. Juan I. Menchaca", Department of Pediatrics, Bone Marrow Transplant Unit, Guadalajara, Jalisco, Mexico.

E-mail address:

Juan C. Lona Reyes, M.D.: carloslona5@hotmail.com

Funding: None.

Conflict of interest: None.

Received: 9-18-2020

Accepted: 10-29-2020

\section{INTRODUCTION}

Primary immunodeficiency diseases (PIDs) are inherent defects in innate and adaptive immunity expressed as frequent and/or severe infections, autoimmune symptoms, lymphoproliferation, allergy, and cancer..$^{1-4}$ There is no information about the worldwide prevalence of PIDs. In Latin America, it has been estimated that the prevalence is 1 event / 516000 inhabitants, but, most likely, it is under-diagnosed. ${ }^{5}$ In Mexico, in recent decades, the number of reported cases has trebled. ${ }^{6}$

In spite of the information available about PIDs, late diagnosis is common. The objective of this study was to describe a case series of PIDs among pediatric patients and the outcome measures associated with survival.

\section{MATERIAL AND METHODS}

This was an observational, retrospective study conducted at Hospital Civil de Guadalajara "Dr. Juan I. Menchaca" (HCGJIM) in the city of Guadalajara, Jalisco, Mexico. HCGJIM provides health services to an open, low-resource population.

The study included patients $\leq 16$ years old who were diagnosed with PID at HCGJIM between January $1^{\text {st }}, 2004$ and December 31 ${ }^{\text {st }}, 2019$. Patients with secondary immunodeficiencies were not included.

Diagnoses and PID classification were made based on the criteria proposed by the International Union of Immunological Societies. ${ }^{7,8}$ The information about outcome measures was obtained from medical records (age at the onset of symptoms and at the time of diagnosis, family and hospitalization history, clinical manifestations, sex, type of PID, treatment, and deaths).

The "delay in diagnosis" was defined as the time elapsed between the onset of symptoms and diagnosis, and the "length of survival" was defined as the time elapsed between the diagnosis of PID and death or until the time of recording information for this study among live patients. Early deaths were those occurring in the first year of life. Parents were considered consanguineous 
if they were biologically related as second cousins or closer.

\section{Statistical analysis}

For qualitative outcome measures, frequencies and percentages were estimated; whereas for quantitative outcome measures, median, minimum, and maximum were estimated. To test the hypothesis, the $\chi^{2}$ test was done to compare proportions and the Mann-Whitney U test, to compare median values. Survival was analyzed using Kaplan-Meier curves with a log rank test to test the hypothesis. The IBM SPSS Statistics software, version 20, was used. The project was approved by the Ethics and Research Committees of HCGJIM under registry no. 0372/20 HCGJIM2020.

\section{RESULTS}

During the study period, 40 patients were diagnosed with PID; their median age was 10.4 months (maximum: 194.6, minimum: 1 ). Also, $75 \%$ (n: 30$)$ were males. Identified PIDs are shown in Table 1.

TABLE 1. Primary immunodeficiencies diagnosed during the study period

\begin{tabular}{|c|c|c|}
\hline & $\mathrm{n}, \%$ & Diagnostic method \\
\hline $\begin{array}{l}\text { Immunodeficiencies affecting humoral } \\
\text { and cell-mediated immunity }\end{array}$ & $13(32.5)$ & \\
\hline Severe combined immunodeficiency & 10 & $\begin{array}{l}\text { Severe lymphopenia, (T-, B+/-, and NK+/-). Low levels of } \\
\text { immunoglobulins, associated with opportunistic infections. } \\
\text { Genetic defect confirmed in } 3(R A G 1, R A G 2 \text {, and IL2RG) }\end{array}$ \\
\hline Hyper-IgM syndrome & 2 & $\begin{array}{l}\mathrm{T}+\text { cells, } \mathrm{B}+\text { cells, high IgM levels, IgG, IgA, and IgE levels below } \\
\text { normal for age. Opportunistic infections (miliary tuberculosis and } \\
\text { cholangitis); } 1 \text { with CD } 40 \mathrm{~L} \text { deficiency and } 1 \text { with CD } 40 \text { deficiency. }\end{array}$ \\
\hline CD4 deficiency & 1 & $\begin{array}{l}\text { T cell (CD3) levels below normal, at the expense of CD4 T cells } \\
\text { (low). Normal B and NK cells. Normal serum immunoglobulins. } \\
\text { Opportunistic infections (chronic suppurative BCG lymphadenitis } \\
\text { and recurrent candidiasis). }\end{array}$ \\
\hline Predominantly antibody deficiencies & $13(32.5)$ & \\
\hline X-linked agammaglobulinemia & 11 & $\begin{array}{l}\text { Very low or absent B cells. Low serum immunoglobulins. Recurrent } \\
\text { bacterial infections (pneumonia, otitis, sinusitis, septic arthritis). }\end{array}$ \\
\hline Common variable immunodeficiency & 2 & $\begin{array}{l}\text { Hypogammaglobulinemia, recurrent infections, } \\
\text { and autoimmunity }(1 / 2) \text {. }\end{array}$ \\
\hline
\end{tabular}

Immunodeficiencies combined with $\quad 8(20)$ syndromic characteristics

Wiskott-Aldrich syndrome $\quad 7 \quad$ Thrombocytopenia, eczema, low weight, chronic diarrhea. No WASp expression (3/7); the rest was diagnosed by association with an affected relative.

\begin{tabular}{lcl} 
Ataxia-telangiectasia & 1 & Ataxia, ocular telangiectasia, pneumonia with lung abscesses. \\
\hline $\begin{array}{l}\text { Congenital defects of phagocyte } \\
\text { number or function }\end{array}$ & $\mathbf{5 ( 1 2 . 5 )}$ & \\
$\begin{array}{l}\text { Severe congenital neutropenia } \\
\text { Glycogen storage disease }\end{array}$ & 3 & $\begin{array}{l}\text { Skin abscesses, recurrent severe infections. Profound neutropenia } \\
\text { (ANC }<100) \text {. ELANE mutation }(1 / 3) .\end{array}$ \\
\hline $\begin{array}{l}\text { Defects in innate and intrinsic immunity } \\
\text { Mendelian susceptibility to mycobacterial } \\
\text { diseases }\end{array}$ & $\mathbf{1 ( 2 . 5 )}$ & Neutropenia, hypoglycemia, hepatomegaly, hyperlipidemia. \\
& 1 & $\begin{array}{l}\text { Progressive, chronic suppurative Mycobacterium bovis and } \\
\text { Mycobacterium abscessus lymphadenitis. } \\
\text { IL-12R } \beta 1 \text { mutation. }\end{array}$ \\
\hline
\end{tabular}

Total 40

RAG: recombination-activating gene; IL2RG: interleukin 2 receptor subunit gamma; CD40L: CD40 ligand; BCG: Bacillus Calmette-Guerin; WASp: Wiskott-Aldrich syndrome protein; ANC: absolute neutrophil count; ELANE: elastase, neutrophil expressed; IL-12R $\beta 1$ : interleukin-12 receptor, beta 1 . 
A family history of PID was observed in 20/40; a history of early death among first-degree relatives, in 21 / 40; and consanguineous parents, in 3 cases. At the time of diagnosis, malnutrition was confirmed in $70 \%$ (n: 28) together with atopic diseases in $32.5 \%$ (n: 13); 3 patients had clinical data of autoimmunity (autoimmune hemolytic anemia in 2 and autoimmune thrombocytopenia in 1). During follow-up, 2 patients developed hematologic neoplasms (acute myeloid leukemia and primary lymphoma of the central nervous system).

Before the diagnosis of PID, $95 \%$ (n: 38) had infections; $87.5 \%$ (n: 35) corresponded to recurrent infections, and $63 \%$ (n: 22) of these affected the upper and/or lower airways. Seven patients developed an adverse event to the Bacillus Calmette-Guerin (BCG) vaccine (3 disseminated infections and 4 , local infections).

The median age at the onset of symptoms was 3.01 months (minimum: 0, maximum: 159.83). When comparing the age at the onset of symptoms based on the PID phenotype, it was observed that immunodeficiencies affecting humoral and cell-mediated immunity (IDHCI) had an earlier onset (median age: 1.67 months, minimum: 0.73, maximum: 11.9), compared to predominantly antibody deficiencies (PADs) (median age: 6.1 months, minimum: 1.57,

FIGURE 1. Delay in diagnosis by primary immunodeficiency phenotype among pediatric patients of Hospital Civil "Dr. Juan I. Menchaca"
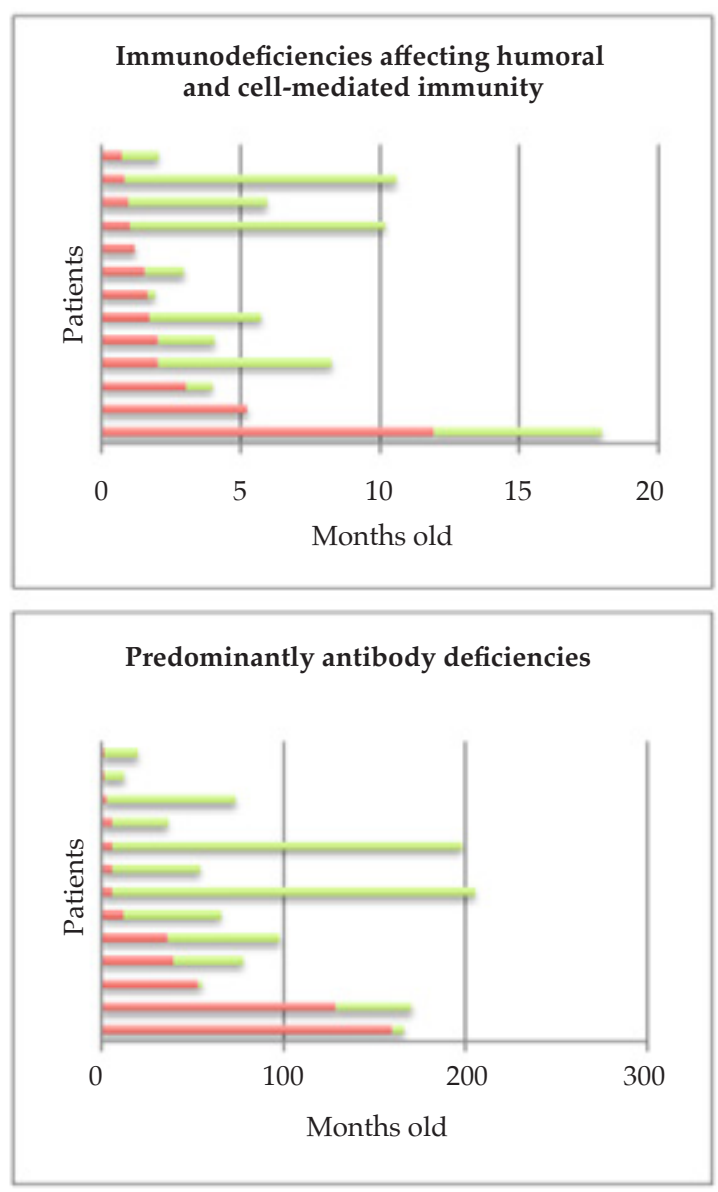

Delay in the diagnosis of PID.

Survival after the diagnosis of PID.
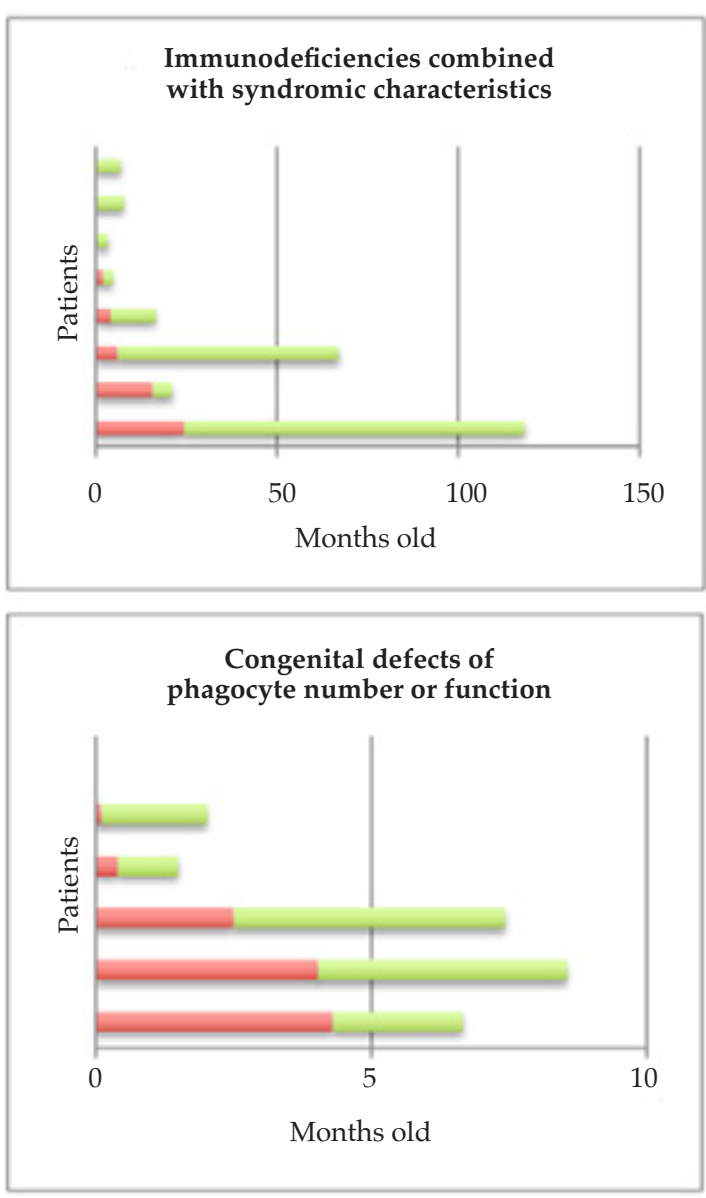
maximum: $159.83 ; p<0.001)$.

The median delay in diagnosis was 6.3 months (minimum: 0, maximum: 199.4). Two patients were diagnosed at the time of the onset of symptoms because they had first-degree relatives with PID. In relation to the delay in the diagnosis by type of PID, it was observed that PADs were diagnosed with a longer delay (median: 41.6 months, minimum: 2.03, maximum: 199.4) compared to IDHCI (median: 2.0 months, minimum: 0.00, maximum: 9.7; $p$ : 0.008) (Figure 1).
To the date of this study, $35 \%$ of patients had died (n: 14). The cause of death was disseminated BCG-itis (3), pneumonia (3), sepsis (2), brain hemorrhage (1), lung abscess (1), abdominal abscess (1), meningoencephalitis (1), adenovirus infection (1), and graft-versus-host disease after bone marrow transplant (1). The remaining patients were receiving specific treatment for their PID phenotype: intravenous or subcutaneous immunoglobulins (13), granulocyte-colony stimulating factor (1), antibiotic prophylaxis (3),

FIGURE 2. Survival curves of patients with primary immunodeficiencies
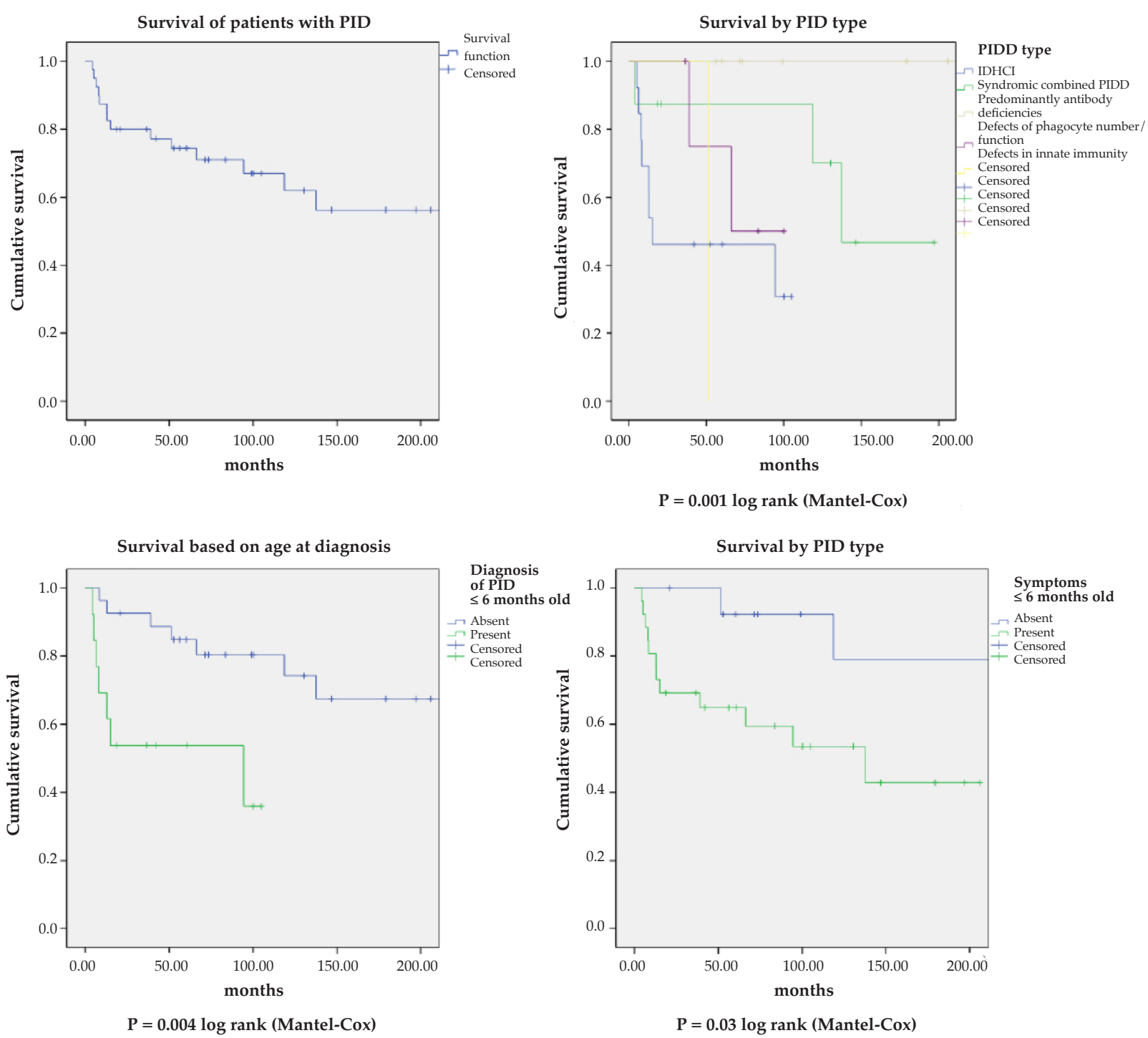

PID: primary immunodeficiency disease; IDHCI: immunodeficiencies affecting humoral and cell-mediated immunity. Censored: patients receiving follow-up who had not died at the time of conducting the study. 
in a protocol for bone marrow transplant (1), and under follow-up after bone marrow transplant (8).

Among patients with IDHCI, $10 \mathrm{had}$ severe combined immunodeficiency (SCID). Of these, 8 underwent a bone marrow transplant; 4 survived; and 1 started the gene therapy protocol, but died due to adenovirus infection. Among children with Wiskott-Aldrich syndrome (WAS), 5 underwent a bone marrow transplant; 4 of them survived.

The analysis of mortality by type of immunodeficiency showed a higher mortality among patients with IDHCI (61.5\% versus $22.2 \%$, $p: 0.038)$, whereas no death was reported among those with PAD (0\% versus $52 \%, p$ : 0.001). Figure 2 shows survival curves.

\section{DISCUSSION}

Patients with IDHCI and those with clinical manifestations or diagnosis of PID in the first 6 months of life showed a lower rate of survival. Infections were the leading cause of death.

Similar to our results, J. Wu et al. described a mortality rate of $38.4 \%$ among 112 patients with PID. The average age at the onset of symptoms and at the time of diagnosis was 13 and 24 months, respectively. The prevalent PIDs were IDHCI $(28.6 \%)$ and, among patients with WAS and SCID, clinical manifestations were observed at a younger age: 1 and 4 months, respectively.

Mellouli et al., ${ }^{2}$ observed that, among patients with PID (n: 710), the average age at the onset of symptoms was 6 months and even younger among those with IDHCI (1.6 months) than those with PADs (90 months). Prevalent PIDs were IDHCI $(28.6 \%)$, and the overall mortality rate was $34.5 \%$, higher in the case of SCID (79 \%).

In patients of HCGJIM with PID, the delay in diagnosis was 6.3 months and even longer among those with PADs. D. Gupta et al., ${ }^{10}$ reported an average delay in diagnosis of 5 years in 120 children with PIDs. However, comparing this indicator by PID type, they observed that the delay was 5 years for PADs and 3 months for in SCID. Late clinical manifestations among patients with PADs may be caused by the transplacental transfer of maternal antibodies and less severe infections compared to IDHCI.

Similar to what has been described in different articles, ${ }^{9-12} 87.5 \%$ of patients included in this series had recurrent infections, mainly affecting the airways, before the diagnosis of PID. Other clinical manifestations of PIDs are signs and symptoms caused by autoimmunity, allergies or malignancies. ${ }^{11,13}$ This study identified 3 patients with autoimmunity and 2 who developed hematologic neoplasms. Lugo Reyes et al., ${ }^{11}$ described, in children with PID, non-infectious manifestations in $36 \%$ of cases (allergies in 17\%, autoimmunity in $19 \%$, neoplasms in $2.4 \%$ ).

Medical records are an important tool to identify patients at a higher risk for PIDs. The family history is useful to justify, in some cases, the screening for PID before the onset of symptoms, while parental consanguinity increases the probability of developing autosomal recessive disorders..$^{2,10,14}$ An early diagnosis is relevant for PIDs. A timely treatment has been associated with better outcomes in terms of survival and adverse events caused by infections. ${ }^{15}$

The limitations of this study were the small number of patients and the retrospective information collection. However, the information observed here is useful to learn about the clinical behavior and course of some PIDs.

\section{REFERENCES}

1. Devonshire AL, Makhija M. Approach to primary immunodeficiency. Allergy Asthma Proc. 2019; v40(6):465-9.

2. Mellouli F, Mustapha IB, Khaled MB, Besbes H, et al. Report of the Tunisian Registry of Primary Immunodeficiencies: 25-Years of Experience (1988-2012). J Clin Immunol. 2015; 35(8):745-53.

3. Benjasupattananan $\mathrm{P}$, Simasathein $\mathrm{T}$, Vichyanond $\mathrm{P}$, Leungwedchakarn $\mathrm{V}$, et al. Clinical characteristics and outcomes of primary immunodeficiencies in Thai children: an 18-year experience from a tertiary care center. J Clin Immunol. 2009; 29(3):357-64.

4. Mahlaoui N, Jais JP, Brosselin P, Mignot C, et al. Prevalence of primary immunodeficiencies in France is underestimated. J Allergy Clin Immunol. 2017; 140(6):1731-3.

5. Mendoza-Quispe D, García-Gomero D, Córdova-Calderón W. Diagnóstico situacional de las inmunodeficiencias primarias: Aproximación preliminar. Rev Peru Med Exp Salud Pública. 2017; 34(2):346-7.

6. Coria Ramírez E, Espinosa Padilla S, Espinosa Rosales F, Vargas Camaño ME, et al. Panorama epidemiológico delas inmunodeficiencias primarias en México. Rev Alerg Mex. 2010; 57(5):159-63.

7. Tangye SG, Al-HerzW, Bousfiha A, Chatila T, et al. Human Inborn Errors of Immunity:2019Updateon the Classification from the International Union of Immunological Societies Expert Committee. J Clin Immunol. 2020; 40(1):24-64.

8. Bousfiha A, Jeddane L, Picard C, Ailal F, et al. The 2017IUIS Phenotypic Classification for Primary Immunodeficiencies. J Clin Immunol. 2018; 38(1):129-43.

9. WuJ, Zhong W, Yin Y, Zhang H. Primary immunodeficiency disease: a retrospective study of 112 Chinese children in a single tertiary care center. BMC Pediatr. 2019; 19(1):410.

10. Gupta D, Thakral D, Kumar P, Kabra S, et al. Primary Immunodeficiency Disorders Among North Indian Children. Indian J Pediatr. 2019; 86(10):885-91.

11. Lugo Reyes SO, Ramírez-Vázquez G, Cruz Hernández A, Medina-Torres E, et al. Clinical Features, Non-Infectious 
Manifestations and Survival Analysis of 161 Children with Primary Immunodeficiency in Mexico: A Single Center Experience Over Two Decades. J Clin Immunol. 2016; 36(1):56-65.

12. Pedraza Á, Vargas-Rumilla MI, Ramírez-Roa JL. Registro de inmunodeficiencias primariaa en niños en un hospital de cuarto nivel. Bogotá, 2010-2016. Rev Alerg Mex. 2018; 65(4):341-8.

13. Jonkman-Berk BM, Van den Berg JM, Ten Berge IJ, Bredius $\mathrm{R}$, et al. Primary immunodeficiencies in The Netherlands: national patient data demonstrate the increased risk of malignancy. Clin Immunol. 2015; 156(2):154-62.

14. BarboucheMR,MekkiN,Ben-AliM,Ben-MustaphaI.Lessons from Genetic Studies of Primary Immunodeficiencies in a Highly Consanguineous Population. Front Immunol. 2017; 8:737.

15. Marciano BE, Huang CY, Joshi G, Rezaei N, et al BCG vaccination in patients with severe combined immunodeficiency: complications, risks, and vaccination policies. J Allergy Clin Immunol. 2014; 133(4):1134-41. 